\title{
CAPTURING MOBILE COLLABORATION IN ACTIVE LEARNING: LESSONS FROM A LONGITUDINAL MIXED METHODOLOGIES STUDY
}

\author{
Peter Ilic \\ Center for Language Research, School of Computer Science and Engineering, University of Aizu, Japan
}

\begin{abstract}
This paper reflects on an attempt to introduce smartphones into a blended learning context and highlights several methodological considerations relevant to the collection of mobile data. While mixed methods are now common, using this approach for investigating the challenges of mobile data collection is not as common. This study employed a mixed method longitudinal exploratory multiple case study design. The study collected qualitative and quantitative data on student interactions within a yearlong series of collaborative language learning activities. This paper describes the methodological issues that emerged during the planning and implementation of the study. The participants were undergraduate students studying English translation at a four-year private university in Tokyo, Japan. This paper adds to the knowledge of employing mixed methodology design for mobile data collection and analysis. In particular the advantages of incorporating Multidimensional Scaling (MDS) analysis with qualitative data. The results suggest that separate forms of data collected at similar frequencies and times and then triangulated provided an effective methodology for studying collaborative learners in a highly mobile context. This can be seen as evidence for the inclusion of various data collection cycles within a single mobile learning research study.
\end{abstract}

\section{KEYWORDS}

Mobile Learning, Mixed Methods, Triangulation, Multidimensional Scaling

\section{INTRODUCTION}

The dramatic impact of smartphone technology on society suggests the potential for a similarly significant effect on education. This study explores a specific sector of education affected by this technology; it focuses on the impact on students from integrating mobile phones in collaborative language learning activities at the university level. The object of the research study designed around the following methodology was to add to the understanding of this interaction, such as, how the affordances mobile technology offers, like anytime and anywhere communication and data gathering, affect student approaches to the activities.

The study demonstrates that valuable results can be gained from such an approach and that the strength of the findings can be increased through triangulation. Also, the design of the data collection frequency was shown to have a relationship with the pattern of triangulation. This finding may be of value to other researchers during the research design phase and the coding phase.

\section{LITERATURE REVIEW}

There is a deep variety of methodologies employed in mobile research. Wu et al. (2012) reviewed 164 papers published from 2003 to 2010 from the perspective of methodology in relation to four research purposes; purpose one being mobile learning systems and the evaluation of their effectiveness, purpose two being designs of mobile systems and the evaluation of their effectiveness, purpose three is investigating the affective domain during mobile learning, and purpose four is designing a mobile system for learning. They discovered that for purpose one, researchers primarily relied on surveys (26 studies), followed by experimental research methods (20) and descriptive methods (7). For purpose two, experimental research methods were used most often (4), followed by surveys (2), descriptive methods (1) and observation (1). For 
purpose three, only two methodologies were used: surveys (6) and interviews (1). For purpose four, surveys were the most commonly used methodology (16), followed by experimental research methods (14), descriptive methods (8), case studies (2) and observation (1). Similarly, Baran (2014) found that for mobile learning in the teacher education literature most methodologies were case studies or mixed method. Data sources they report included questionnaires, interviews, blogs, recordings, observations, journals, artefacts, usage data, and audio and video transcripts.

\section{STUDY DESIGN}

The research design presented here is a case study to explore the impact of mobile phones on collaborative learning activities in a university setting. The methodology utilised in this study can best be described as a longitudinal mixed methodology (qualitative and quantitative data), exploratory, multiple case study approach adopted for a period of one academic year. The objective was to gain a greater understanding of the processes and consequences that result from incorporating mobile phone interaction capabilities into collaborative learning activities for Japanese university undergraduates.

The participant sample in this study was drawn from a larger population of undergraduate students studying English as a foreign language at a four-year private university in Tokyo, Japan. The students were all between the ages of 18 and 20 years and living in Japan during the study period. Four groups of between five to eight members were formed from volunteers and followed a three-step process. A gender balance of males and females was attempted but was infeasible owing to the high percentage of female students in the school. Group one had 5 girls and 2 boys, group 2 had 8 girls, group 3 had 6 girls, and group 4 had 6 girls.

\section{DATA COLLECTION}

Evaluating mobile device use is challenging because of the wide variety of usage patterns (Trinder, Roy, \& Magill, 2009), locations, and circumstances, in which they are employed make it infeasible to follow the user around. When compared to laptops or fixed computers, mobile or pervasive technologies present a challenge to methodology designers (Lim \& Rogers, 2008). For this reason, a range of both qualitative and quantitative data was gathered so as to provide a wide "net" with which to capture a diverse range of data.

Quantitative data collection followed van'T Hooft's (2009) proposed six types of quantitative research data for collection with mobile devices were followed; spatial data indicating where the device is being operated; temporal data indicating when the device is being used; user data showing what they are being employed for; learner data indicating what content is being accessed; connectivity data recording who the learner communicates with; assessment data which deals with how the learners know that they are learning and what they are learning. This study incorporated the collection of spatial data through a short survey done during each mobile log in, but no specific location coordinate data was collected. The website logs recorded temporal data of website entry and actions (Figure 2) but could not resolve the precise time spent online. The online time was worked in as an interview question to obtain an approximate sense of how long the participants spent online during each activity. User data was gathered on the actions while logged into the research website to provide a coherent picture of how they carried out the activities. Also, the MDS data was collected to provide a visual representation of any changes in relationship between user and device in the context of the activities (Figure 3). The learner data was recorded and included all online actions and artefacts related to the collaborative activity (Figure 2). The connectivity data was gathered solely for the forum post interaction logs, but any contact outside of the Moodle course website was not recorded in the website logs. The students could declare any alternative communication channels (Twitter, Facebook, face-to-face, etc.) employed each week by filling out their weekly E-Journal which is similar to log books used in some studies (Corlett, Sharples, Bull, \& Chan, 2005). The course assessment data comprised the forum answers but was not part of this study because the researcher wished to separate any grading of student participants and the research. 


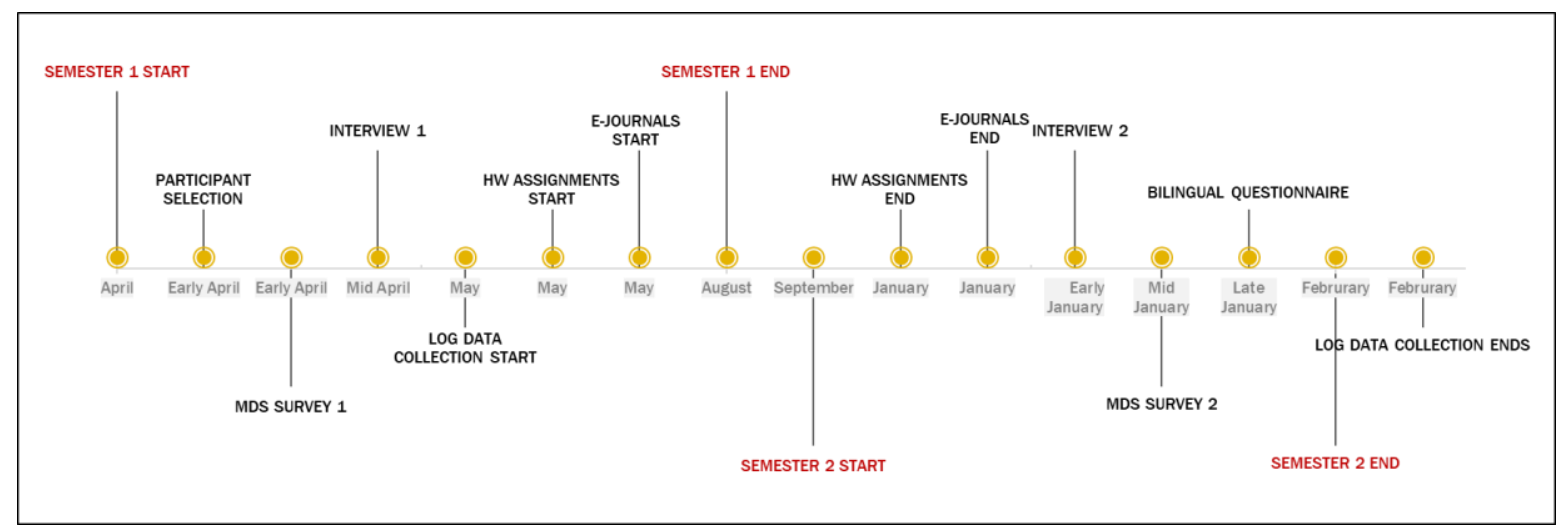

Figure 1. Study Timeline

Qualitative data generally consists of attitude surveys, interviews, and questionnaires which typically rely on memory after the event for developing theory and interpretations from the perspective of the individuals being studied (Ezzy, 2002). Theoretical questions and answers were continuously updated in an ongoing dialogue with the experience being investigated which in turn allowed for the transformation of interview questioning producing a much more sophisticated understanding of the experience under study (Ezzy, 2002). This process of examining the data as it is collected continued until a point of saturation had been attained where the researcher could find nothing new (Glaser \& Strauss, 1967).

A timeline of the major data collection periods can be seen in Figure 1. Student online website log data, e-journals, student artefacts, and face-to-face interviews comprised the principal sources of data. Retrospective interviews were also carried out to resolve the queries raised from preliminary examination of student e-journals, artefacts submitted such as posted comments to the website, and online logs. Website data aggregation Triangulation was employed to strengthen the validity of findings by correlating data from these various sources and noting when they converged on a similar result (Mathison, 1988).
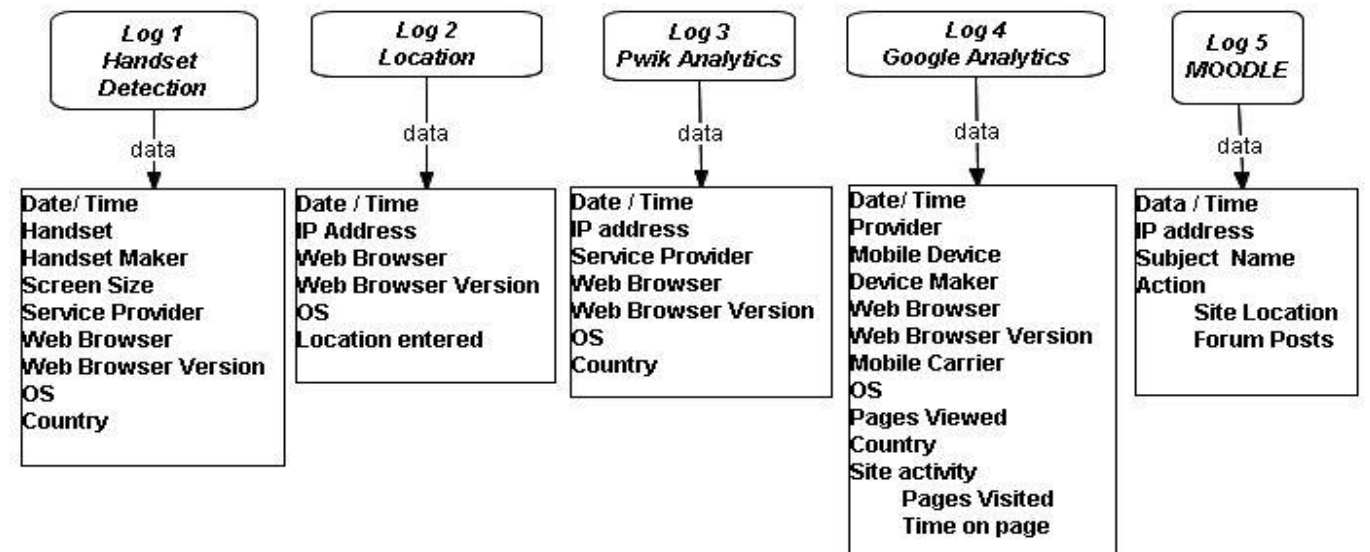

Figure 2. Log Data Collected

\subsection{Web Site Logs}

Several computer logging systems were employed to monitor the participants' interaction with the website. These logging systems enabled the researcher to distinguish interesting usage patterns that could be later correlated with the other findings. The array of data compiled from these logging systems is set out in Figure 2. All initial entrance to the Moodle page went through Handset Detection service which distinguishes the entry device - mobile phone, tablet, computer, etc.- characteristics.

The e-journals and the final questionnaire proved to be rich sources of data. Many of the findings from the interviews and other data sources were corroborated through triangulation with the e-journals and questionnaire; this can be seen in. In addition, they provided a way to monitor back channel communications between students that took place outside of the course CMS. 
Artefacts in this research refer to text, video, picture, audio, or any other files that students made while using their mobile phone. The activities used in this study was in the form of small group collaborative learning activities consisting of weekly modules that were accessible on private class website by either mobile phone or computer. These activities consisted of homework questions related to translation issues that are relevant when moving between the Japanese and English languages.

Two semi-structured individual interviews were conducted over one academic year. The first was held at the tail end of the first semester; the intention was to obtain information on participant attitudes to using mobile phones and to ensure that they were completing the weekly homework activities without difficulty. The second interview was held at the end of the second semester and consisted of follow-up questions from the first interview and any clarification questions required to explain access patterns.

\section{DATA ANALYSIS}

\subsection{Qualitative Data Analysis}

The qualitative coding included the interviews, website logs, location survey, e-journals, questionnaire, and artefacts. The first stage of data analysis was content analysis, the organising, tracking, categorizing, and contextualizing the data obtained at distinct stages within QSR International's NVivo 10 Software to improve the reliability of the study (Maxwell, 1996; Stake, 1995; Wickham \& Woods, 2005; Yin, 2009). A inductive form of thematic analysis coding (Ezzy, 2002) was adopted to identify themes or concepts in the data, build a systematic account of what has been observed, identify any emergent theory, and highlight issues and problems not anticipated.

\subsection{Quantitative Data Analysis}

In this study, at the beginning and the end of the data collection period, the participants were given an online word association questionnaire to complete, and the results were analysed using a MDS technique. MDS is a method for capturing efficient information from observed dissimilarity data by representing the data structure in lower dimensional spatial space. The reasoning behind using this technique was that it could provide a picture of how students perceived mobile technology in relation to the other aspects of their school life within the context of the study. By comparing this image pre-study and post-study, any changes in their views may be observable.

MDS is a well-known group of data analysis techniques which spatially represent the data's structure to make it easier to assimilate. In this study, the purpose for using MDS was to obtain a picture of the participants' relationship to school in general, homework, and mobile phones. It was expected that by analysing these word association questionnaires, the researcher could observe any variation in participant attitudes in the changing relational position of the words.

The output from MDS is in a two-dimension plot (Figure 3) of all the objects (words), and the distance between them indicates the value of dissimilarity. The closer the words appear visually in the plot the stronger the participants' perceived similarity between them. The advantage of MDS is that it represents the data spatially to allow a visual interpretation of the distances between the points plotted in two dimensions, so the interpretation of distance is visual. As mentioned, there are two sets of data: one from semester one and one from semester two. These two data sets were combined into a super matrix which allowed any pre and post data change in perceived similarity value reported by the participants between the beginning and end of the study to be represented by a movement in the second set of plotted points. The first set of data points are represented by the number of the word, followed by the letter "a," so all numbers followed by the letter "a" are from the semester one response data. Likewise, the second set of data is the number of the word followed by the letter "b," so all numbers followed by a "b" are from the second semester responses. The arrows were added later to indicate any change in the position of the points which represent a change in the perceived similarity of the words among all the participants. When a word is recorded as moving closer to another word, it indicates that the second semester data point has shifted closer to another second semester word, which suggests those two words are now perceived as having more in common at the end of the study than at the beginning. This information combined with the other data sources in this research enhanced the triangulation. 
Here we can see that the MDS results correlated around research questions one, two and three. In Figure 4, the MDS analysis is in cluster B along with "Interview 1", "Interview 2", and "Final Questionnaire" indicating that the findings from the original MDS analysis in Figure 3 closely correlated with data from these three sources.
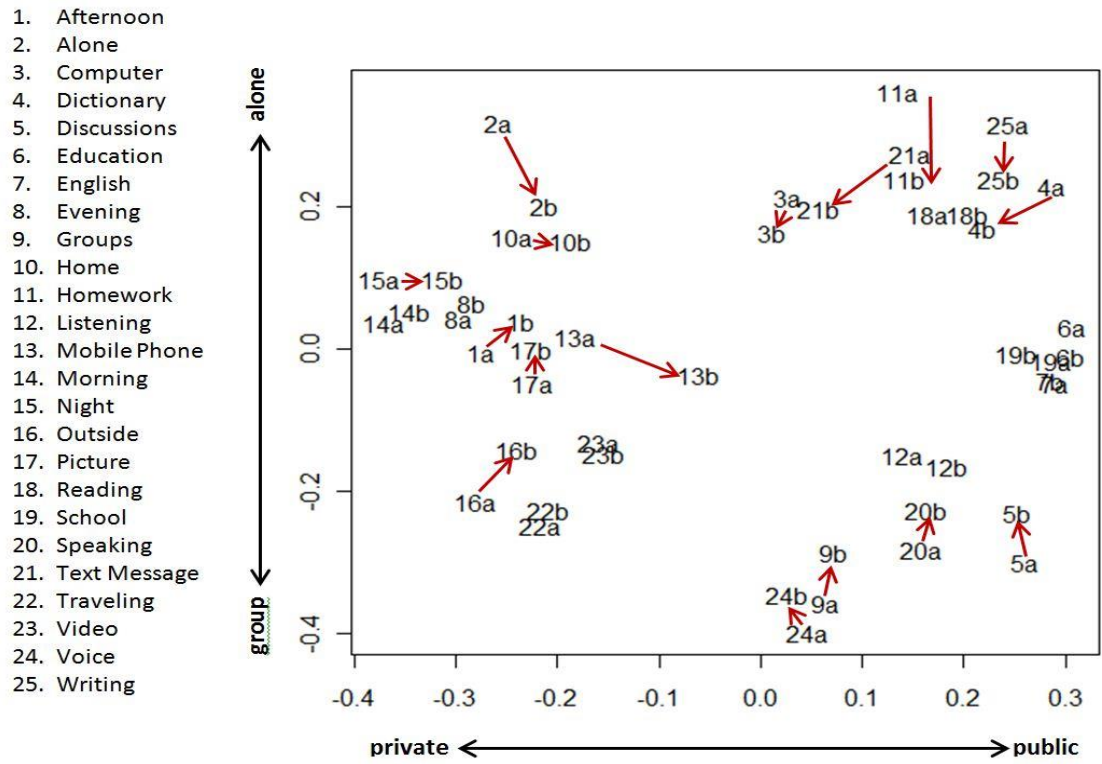

Figure 3. MDS Plot All Groups

\subsection{Triangulation}

Many mobile learning research projects have utilised interviews, questionnaires, diaries, and focus groups to collect information (Sharples, 2009). When these methods are employed individually, in mobile research (Traxler, 2007) as well as other forms of research (Wali, Oliver, \& Winters, 2009) there can be uncertainty in the reliance on the memory and honesty of participants. In this study, an additional problem with relying on users to articulate their actions is that they may not possess the language skills to report their experiences. Triangulation is a research strategy that incorporates several such research methods in a single research study to yield a more comprehensive view, to clarify a complex phenomenon, or when a conventional approach generates a distorted picture (Cohen, Manion, \& Morrison, 2007). Also, it can strengthen the validity of findings, such as when data from disparate sources or compiled with diverse methods "converge" (Mathison, 1988) on the same result.

The value of the triangulation is clear from large number of supporting data points for each code represented. The data points are both qualitative and quantitative so supporting the idea that mixed methodology studies can provide a rich multidimensional view of a complex collaborative activity such as mobile learning. The clarify this point, in Figure 4 this same data has been analysed using MDS to produce a two-dimensional plot of the triangulation data in Figure 4: MDS Analysis of Data Triangulation. In this plot, the distance between the data sources represents the similarity - the number of times the data sources supported each other. There are three clear outliers; these include "Time online", Read Write Count, and "Location." "Time online" can be explained by the technical difficulties in measuring mobile connect time as discussed earlier. This made the data source unreliable alone which made the researcher hesitant to use it. "Location" data was collected from the small three-question survey the students were to answer each time they connected to the mobile website. However, it was found through the interviews that many students set book marks for the mobile site which linked to internal pages of the website so bypassing the small location survey. This again meant that the data was not utilised to a great extent because the number of student answers was limited. The "RW Count" was accurately measured but appears to have had little impact on the triangulation of data. This may have been an oversight on the part of the researcher or could mean that the data was of little value. This could be an area for further research. 


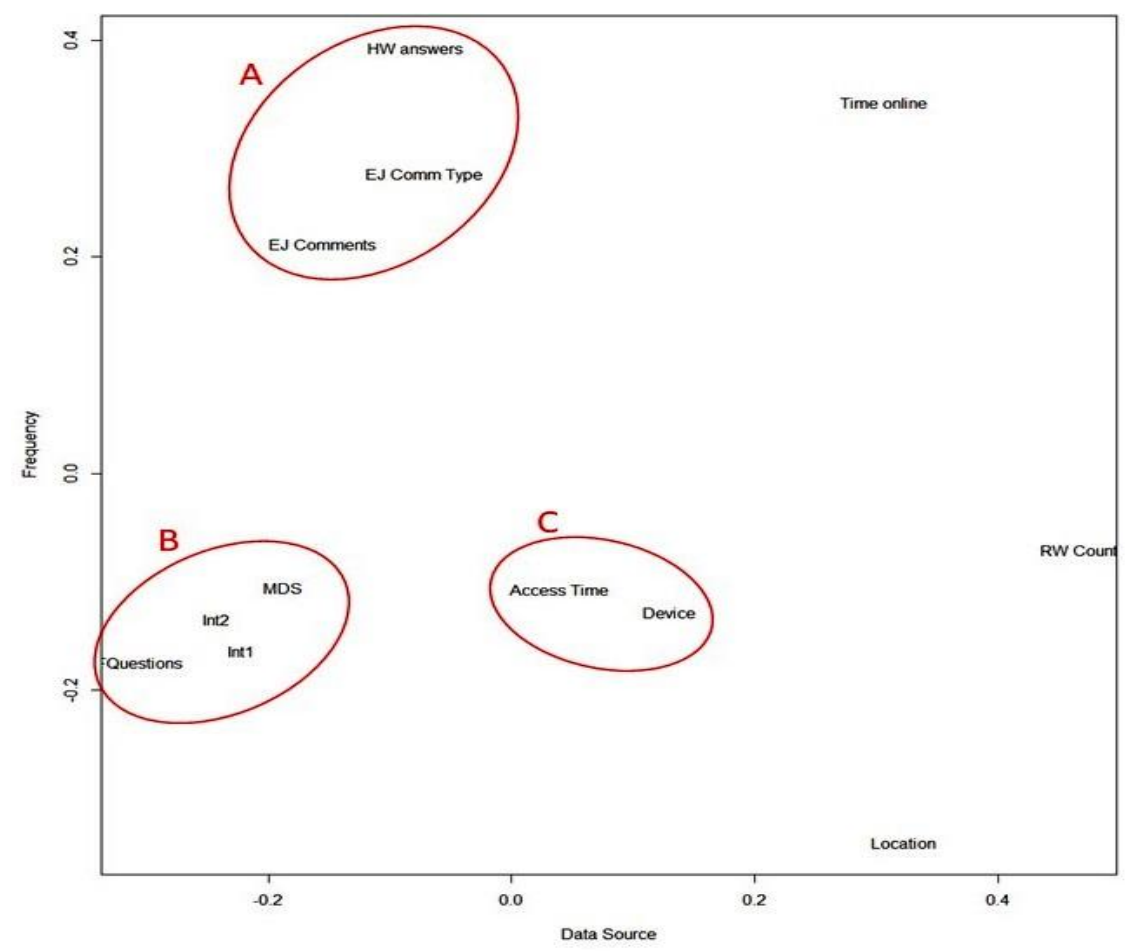

Figure 4. MDS Analysis of Data Triangulation

Cluster A includes "Homework Answers", E-Journal Communication Types", and "E-Journal Comments". One possible explanation for this cluster is that this data was collected on a weekly basis at the same time as the homework activities. This means that the issues directly related to homework completion and submission would likely appear in these three sources. If a participant had trouble with a homework discussion online they would likely mention it in their weekly E-Journal along with the type of problem -face-to-face, texting, etc. This can be seen with the code "ease and speed of use" which is supported by these same three sources. Cluster B includes "MDS Analysis" (Figure 5), "Interview 1", "Interview 2", and "Final Questionnaire." These four sources were clearly separate from the course in which the homework assignments were completed. Without the final questionnaire these took place twice during the research which may account for the similarity of topics. Also, they were heavily affected by the researcher reflections during the ongoing process of exploratory research. The interviews and the final questionnaire provided a way to collect the participants' detailed views of the experience of working with the mobile devices. An example of this is the code "increased control" under research question one.

These results suggest that separate forms of data collected at similar frequencies and times may increase the likelihood of triangulating those data. Again, this can be seen as evidence for the importance of various data collection cycles within a single research study. Cluster A was a weekly collection cycle and the three types of data collected clearly supported each other. The same can be seen for the yearly collection cycle in cluster B. The distance between these clusters indicates that there were fewer triangulated data points between the clusters then there was within them. One question that must be asked is whether this reduced triangulation between cluster A and cluster B data sources is due to differences in data findings alone or researcher actions. The coding phase of the research involves several iterations to isolate the codes but this result suggests that a deeper comparison of the findings between these two clusters may yield another layer of codes.

\section{CONCLUSION}

This research study provides several implications for further mobile learning research. In terms of methodology related recommendations that may overcome issues with mobile data collection and mobile 
interface. The results suggest that separate forms of data collected at similar frequencies and times increases the likelihood of triangulating data points so compensates for the difficulties related with studying this fluid phenomenon. This can be seen as evidence for the importance of various data collection cycles within a single mobile research study. The researcher feels that these multiple data sources and case study design did add to the validity and reliability of the findings in this research by providing many points of data triangulation. The difficult of studying a phenomenon of this type that takes place at all times of the day and in all imaginable spaces is clear. The log data provided an invaluable source of confirmation for the interview data and the MDS plot provided a further graphic representation that greatly help in identifying changes that correlated across data sources.

In the future, the relationship to the mobile phones and the position they hold in student lives could be better understood through another a series of longitudinal studies following the same methodology. Since the relationship that students have with technology changes as fast as the technology advances, this could include a new cohort of students each year for several years. Each progressive year will have had a different history with the technology, and it is this slight difference that could provide important insights on the relationship between mobile device affordances and learning.

\section{REFERENCES}

Adams, R. S., \& Tracey, T. J. (2004). Three versions of the Interpersonal Adjective Scales and their fit to the circumplex model. Assessment, 11(3), 263-270.

Balakrishnan, M., Mohomed, I., \& Ramasubramanian, V. (2009). Where's that phone?: geolocating IP addresses on $3 G$ networks. Paper presented at the Proceedings of the 9th ACM SIGCOMM conference on Internet measurement conference.

Baran, E. (2014). A review of research on mobile learning in teacher education. Journal of Educational Technology \& Society, 17(4), 17.

Bimler, D., \& Kirkland, J. (2001). School truants and truancy motivation sorted out with multidimensional scaling. Journal of Adolescent Research, 16(1), 75-102.

Blaikie, N. W. H. (1991). A critique of the use of triangulation in social research. Quality and Quantity, 25(2), 115-136.

Chang, M., Chin-Yeh, W., \& Gwo-Dong, C. (2009). National program for e-Learning in Taiwan. Journal of Educational Technology \& Society, 12(1), 5.

Cohen, L., Manion, L., \& Morrison, K. (2007). Research methods in education (6th ed.). London ; New York: Routledge.

Corlett, D., Sharples, M., Bull, S., \& Chan, T. (2005). Evaluation of a mobile learning organiser for university students. Journal of Computer Assisted Learning, 21(3), 162-170. doi:10.1111/j.1365-2729.2005.00124.x

Creswell, J. W. (2007). Qualitative inquiry \& research design : choosing among five approaches (2nd ed. ed.). London: SAGE.

Crowe, A., \& van't Hooft, M. (2006). Technology and the prospective teacher: Exploring the use of the TI- 83 handheld devices in social studies education. Contemporary Issues in Technology and Teacher Education, 6(1), 99-119.

DeJordy, R., Borgatti, S. P., Roussin, C., \& Halgin, D. S. (2007). Visualizing proximity data. Field Methods, 19(3), 239-263.

Denzin, N. K. (1989). The research act : a theoretical introduction to sociological methods (3rd ed.). Englewood Cliffs, N.J.: Prentice Hall.

Dougiamas, M. (1999, 2007). Moodle. 1.9. Retrieved from http://moodle.org

Everitt, B., \& Rabe-Hesketh, S. (1997). The analysis of proximity data. London: Arnold ;J. Wiley.

Ezzy, D. (2002). Qualitative analysis : practice and innovation. London: Routledge.

Glaser, B. G., \& Strauss, A. L. (1967). The discovery of grounded theory; strategies for qualitative research. Chicago,: Aldine Pub. Co.

Guba, E. G., \& Lincoln, Y. S. (2005). Paradigmatic controversies, contradictions, and emerging confluences, In The Sage Handbook of Qualitative Research (3rd ed.). Thousand Oaks: Sage.

Hooft, M. V. T. (2009). Researching Informal and Mobile Learning: Leaveraging the Right Resources. In G. Vavoula, N. Pachler, \& A. Kukulska-Hume (Eds.), Researching Mobile Learning. Bern: Peter Lang.

Hwang, G.-J., \& Tsai, C.-C. (2011). Research trends in mobile and ubiquitous learning: a review of publications in selected journals from 2001 to 2010. British Journal of Educational Technology, 42(4), E65-E70. doi:10.1111/j.14678535.2011.01183.x

Ilic, P. (2015). The Effects of Mobile Collaborative Activities in a Second Language Course. International Journal of Mobile and Blended Learning (IJMBL), 7(4), 16-37. 
Jick, T. D. (1979). Mixing Qualitative and Quantitative Methods: Triangulation in Action. Administrative Science Quarterly, 24(4), 602-611.

Jonassen, D. H., \& Rohrer-Murphy, L. (1999). Activity Theory as a Framework for Designing Constructivist Learning Environments. Educational Technology Research and Development, 47(1), 61-79.

Kuutti, K. (1996). Activity Theory as a Potential Framework for Human-Computer Interaction Research. In B. A. Nardi (Ed.), Context and consciousness : activity theory and human-computer interaction (pp. 17-44). Cambridge, Mass.: MIT Press.

Kvale, S., \& Brinkmann, S. (2009). InterViews : learning the craft of qualitative research interviewing (2nd ed. ed.). Thousand Oaks ; London.: Sage Publications.

Lim, Y.-k., \& Rogers, Y. (2008). A Framework and an Environment for Collaborative Analysis of User Experience. International Journal of Human-Computer Interaction, 24(6), 529-555. doi:10.1080/10447310801971204

Maeda, E., \& Ritchie, L. D. (2003). The concept of shinyuu in Japan: A replication of and comparison to Cole and Bradac's study on US friendship. Journal of Social and Personal Relationships, 20(5), 579-598.

Mathison, S. (1988). Why Triangulate? Educational Researcher, 17(2), 13-17.

Maxwell, J. A. (1996). Qualitative research design: an interactive approach. Thousand Oaks, Calif: Sage.

Miles, M. B., \& Huberman, A. M. (1994). Qualitative data analysis : an expanded sourcebook (2nd ed. ed.). Thousand Oaks, Calif. ; London: Sage.

Nagino, G., Shozakai, M., Tomoki, T., Saruwatari, H., \& Shikano, K. (2008). Building an effective speech corpus by utilizing statistical multidimensional scaling method. IEICE TRANSACTIONS on Information and Systems, 91(3), 607-614.

Nardi, B. A. (1996). Studying Context: A Comparison of Activity Theory, Situated Action Models, and Distributed Cognition. In B. A. Nardi (Ed.), Context and consciousness : activity theory and human-computer interaction (pp. 69-102). Cambridge, Mass.: MIT Press.

Nunan, D. (1992). Research methods in language learning: Cambridge University Press.

Oltman, P. K., \& Stricker, L. J. (1990). Developing homogeneous TOEFL scales by multidimensional scaling. Language Testing, 7(1), 1-12.

Pachler, N. (2010). Mobile learning : structures, agency, practices. New York: Springer.

Patton, M. Q. (1980). Qualitative evaluation methods. Beverly Hills: Sage Publications.

Petrova, K., \& Li, C. (2009). Focus and setting in mobile learning research: A review of the literature. Communications of the IBIMA, 10(26), 219 - 226.

Saldana, J. (2009). The coding manual for qualitative researchers. Thousand Oaks, CA: Sage.

Savenye, W. C., \& Robinson, R. S. (2004). Qualitative research issues and methods: An introduction for educational technology. In D. H. Jonassen (Ed.), Handbook of research on educational communications and technology. (pp. 1021-1043). Mahwah, N.J: Lawrence Erlbaum.

Sharples, M. (2009). Methods for evaluating mobile learning. In G. Vavoula, N. Pachler, \& A. Kukulska-Hulme (Eds.), Researching Mobile Learning (pp. 17-39). Oxford: Peter Lang.

Silverman, D. (1985). Qualitative methodology and sociology : describing the social world. Aldershot, Hants, England ; Brookfield, Vt., U.S.A.: Gower Pub. Co.

Silverman, D. (2009). Doing qualitative research (3rd ed.). Thousand Oaks, CA: Sage Publications.

Simon, S. A., \& Eby, L. T. (2003). A typology of negative mentoring experiences: A multidimensional scaling study. Human Relations, 56(9), 1083-1106.

Sireci, S. G., \& Geisinger, K. F. (1992). Analyzing test content using cluster analysis and multidimensional scaling. Applied Psychological Measurement, 16(1), 17-31.

Song, Y., \& Fox, R. (2008). Using PDA for undergraduate student incidental vocabulary testing. ReCALL, 20(3), 290-314.

Stake, R. E. (1995). The art of case study research. Thousand Oaks ; London: Sage Publications.

Traxler, J. (2007). Defining, Discussing and Evaluating Mobile Learning: The moving finger writes and having writ. The International Review of Research in Open and Distance Learning, 8(2).

Trinder, J., Roy, S., \& Magill, J. (2009). Using Automated Loggingto Collect Information on Mobile Usage for Learning. In G. Vavoula, N. Pachler, \& A. Kukulska-Hume (Eds.), Researching Mobile Learning. Bern: Peter Lang.

Wali, E., Oliver, M., \& Winters, N. (2009). Are They Doing What They Think They're Doing?: Tracking and Triangulating Students' Learning Activities and Self Reports. In N. Pachler, A. Kukulska-Hulme, \& G. Vavoula (Eds.), researching Mobile Learning (pp. 317-335). Oxford: Peter Lang.

Wickham, M., \& Woods, M. (2005). Reflecting on the strategic use of CAQDAS to manage and report on the qualitative research process. The Qualitative Report, 10(4), 687-702.

Wu, W.-H., Jim Wu, Y.-C., Chen, C.-Y., Kao, H.-Y., Lin, C.-H., \& Huang, S.-H. (2012). Review of trends from mobile learning studies: A meta-analysis. Computers \& Education, 59(2), 817-827. doi:10.1016/j.compedu.2012.03.016

Yin, R. K. (2009). Case study research : design and methods (4th ed.). Los Angeles, Calif.: Sage Publications. 